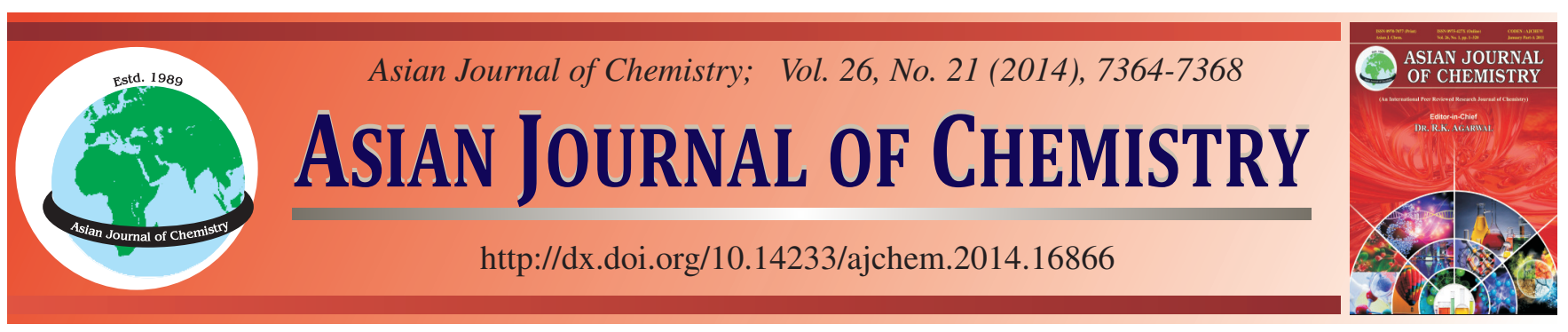

\title{
Green Synthesis, Physicochemical and Polarity Studies of Some Novel Biologically Active Donor Acceptor Chromophores
}

\section{Salman A. Khan ${ }^{1, *}$, Abdullah M. Asiri ${ }^{1,2}$, Samy A. El-Daly ${ }^{1,3}$, Hadi M. Marwani ${ }^{1,2}$ and Khalid A. Alamry ${ }^{1}$}

\author{
${ }^{1}$ Department of Chemistry, Faculty of Science, King Abdulaziz University, P.O. Box 80203, Jeddah 21589, Saudi Arabia \\ ${ }^{2}$ Center of Excellence for Advanced Materials Research (CEAMR), King Abdulaziz University, P.O. Box 80203, Jeddah 21589, Saudi Arabia \\ ${ }^{3}$ Chemistry Department, Faculty of Science, Tanta University, Tanta, Egypt
}

*Corresponding author: Fax: +966 2 6952292; Tel: +966 2 6952293; E-mail: sahmad_phd@yahoo.co.in

\begin{abstract}
Chalcones were synthesized by the reaction of acetyl ferrocene and corresponding aldehhyde under microwave irradiation. Results obtained from spectroscopic (FT-IR, ${ }^{1} \mathrm{H}$ NMR, ${ }^{13} \mathrm{C}$ NMR, EI-MS) and elemental analysis of synthesized compounds was in agreement with their chemical structures. UV-visible and fluorescence spectroscopy measurements provided that compound $\mathbf{1}$ and $\mathbf{2}$ are good absorbent and fluorescent. Fluorescence polarity study demonstrated that these compounds were sensitive to the polarity of the microenvironment provided by different solvents. In addition, spectroscopic and physicochemical parameters, including electronic absorption, extenction coefficient, Stokes shift, oscillator strength and transition dipole moment, were investigated in order to explore the analytical potential of synthesized compounds. The antibacterial activity of the compound $\mathbf{1}$ and $\mathbf{2}$ were first studied in vitro by the disk diffusion assay against two Gram-positive and two Gram-negative bacteria. The minimum inhibitory concentration was then determined with the reference of standard drug chloramphenicol.
\end{abstract}

Keywords: Chalcones, Physicochemical, Antibacterial activity, Chloramphenicol.

\section{INTRODUCTION}

Donor acceptor conjugated chromophores are defined the chromophores which have an electron donor group (D) and an electron accepter (A) group that exhibit intramolecular charge transfer through the $\pi^{1,2}$. The compounds which have end-capped with electron donating and accepting group arranged in either symmetrical A- $\pi-A, D-\pi$-D or asymmetrical A- $\pi$-D are known as chromophore orientations ${ }^{3}$. The molecules having the donor acceptor conjugated framework have been largely investigated for optical-electrical applications from photophysical studies such as nonlinear optical properties ${ }^{4}$, photonic materials ${ }^{5}$, devices ${ }^{6}$, optical limiting ${ }^{7}$, electrochemical sensing ${ }^{8}$, light-emitting devices ${ }^{9}$, langmuir film ${ }^{10}$ and solar cell materials ${ }^{11}$.

Chalcones are one of the compounds which have donor acceptor framework. Several reactions were reported for the synthesis of donor acceptor chromophores ${ }^{12}$. However, aldol condensation is one of the most important reactions for the formation of donor acceptor chromophores by the nucleophilic addition reaction ${ }^{13}$. Various synthetic methods have been reported so far, such as refluxing in an organic solvent ${ }^{14}$, the solvent-free solid-phase reaction ${ }^{15}$, ultrasonication ${ }^{16}$, photosen- sitization $^{17}$ and microwave radiation ${ }^{18}$. Chalcone derivatives also reported earlier as important probes of medium viscosity ${ }^{19}$. This property is particularly important in assessing the microenvironments in micelles, microemulsions and vesicles ${ }^{20}$. Chalcones are known as physiological active substances produced within tissues that appear to control the mitosis of the cell of specific tissues that produce them ${ }^{21}$. Hetero-aryl chalcone derivatives have several applications in many areas. They have been applied in food industry ${ }^{22}$, fluorescent probes for sensing $\mathrm{DNA}^{23}$ and photoreactive polymers ${ }^{24}$. Also, chalcones have been used for numerous optical applications including photo-alignment layer of liquid crystal display ${ }^{25}$.

Due to whiled applications of the donor-acceptor chromophores (chalcones). In this paper we are reporting the synthesis of novel chalcones by green synthesis and their Physicochemical studies such as electronic absorption, molar absorptivity, oscillator strength and dipole moment of donor acceptor chromophores were also determined.

\section{EXPERIMENTAL}

Acetyl ferrocene and corresponding active aldehyde were purchased from Acros Organic. Other reagents and solvents 
(A.R.) were obtained commercially and used without further purification, except dimethylformamide, ethanol and methanol.

Melting points were recorded on a Thomas Hoover capillary melting apparatus without correction. FT-IR spectra were recorded on a Nicolet Magna 520 FT-IR spectrometer. ${ }^{1} \mathrm{H}$ NMR and ${ }^{13} \mathrm{C}$ NMR experiments were performed in $\mathrm{CDCl}_{3}$ on a Brucker DPX $600 \mathrm{MHz}$ spectrometer using tetramethyl silane (TMS) as internal standard at room temperature. UV-visible electronic absorption spectra were acquired on a Shimadzu UV-1650 PC spectrophotometer. Absorption spectra were collected using a $1 \mathrm{~cm}$ quartz cell. Steady state fluorescence spectra were measured using Shimadzu RF 5301 PC spectrofluorphotometer with a rectangular quartz cell. Emission spectra were monitored at right angle. All fluorescence spectra were blank subtracted before proceeding in data analyses.

General method for the synthesis of chalcones: To a solution of acetyl ferrocene $(0.34 \mathrm{~g}, 2.5 \mathrm{mmol})$ and corresponding active aldehyde $(2.5 \mathrm{mmol})$ in dry ethanol $(20 \mathrm{~mL})$ taken in a beaker $(100 \mathrm{~mL})$, a catalytic quantity of potassium hydroxide $(0.05 \mathrm{~g}, 1.25 \mathrm{mmol})$ was added and the reaction mixture was heated inside a microwave oven for 48-62 s (at $210 \mathrm{~W}$, i.e. about $30 \%$ microwave power $)^{26-28}$. The reactions were monitored through TLC using solvent system ethyl acetate:benzene $(2: 8)$, when the reaction was complete the reaction mixture was cooled in an ice bath and the product thus formed was filtered, washed with ethanol followed by washing with water till the washings were neutral and recrystallized from distilled ethanol and chloroform (Scheme-I and Table-1).

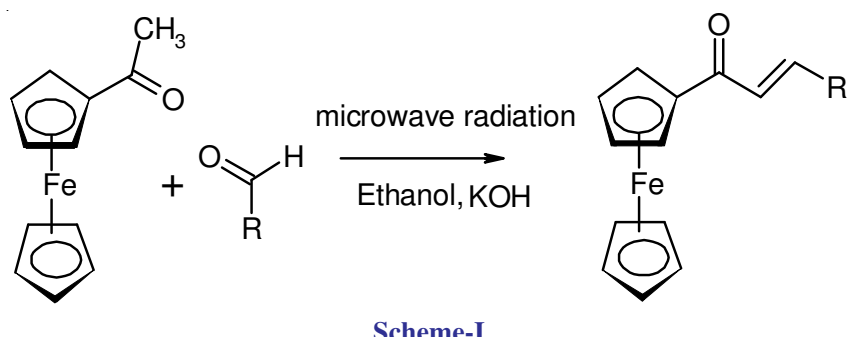

1-Ferrocenyl-3-(9-ethyl-9H-carbazol-3-yl)-2-propen1-one (1): m.p. $163{ }^{\circ} \mathrm{C}$; EI-MS m/z (rel. int. \%): 434 (78) [M $+1]^{+}$; IR $\left(\mathrm{KBr}, v_{\max }, \mathrm{cm}^{-1}\right): 2980(\mathrm{C}-\mathrm{H}), 1685(\mathrm{C}=\mathrm{O}), 1571$ $(\mathrm{C}=\mathrm{C}) ;{ }^{1} \mathrm{H}$ NMR $\left.(600 \mathrm{MXz} \mathrm{CDCl})_{3}\right) \delta: 8.62(\mathrm{~s}, \mathrm{CH}), 8.38(\mathrm{~s}$, $\mathrm{CH}), 8.18(\mathrm{~d}, \mathrm{CH}, J=7.7 \mathrm{~Hz}), 8.13(\mathrm{dd}, \mathrm{CH}, J=7.8 \mathrm{~Hz}), 8.05$ $(\mathrm{d}, \mathrm{CH}, J=15.6 \mathrm{~Hz}), 7.81$ (d, CH, 8.4 Hz), 7.55-7.28 (m, 4H,
$\mathrm{CH}), 7.21(\mathrm{~d}, \mathrm{CH}, J=15.6 \mathrm{~Hz}), 4.97(\mathrm{~s}, 2 \mathrm{H}$, ferrocene), 4.59 (s, 2H, ferrocene), 4.42 ( $\left.\mathrm{t}, \mathrm{CH}_{2}-\mathrm{CH}_{3}\right), 4.24$ (s, 5H, ferrocene), $1.48\left(\mathrm{q}, \mathrm{CH}_{2}-\mathrm{CH}_{3}\right) ;{ }^{13} \mathrm{C} \mathrm{NMR}\left(\mathrm{CDCl}_{3}\right) \delta: 193.12,191.84$, $142.45,141.22,140.48,126.74,126.16,126.29,123.49$, 122.86, 121.29, 120.82, 120.67; Anal. (\%) calc. for $\mathrm{C}_{27} \mathrm{H}_{23} \mathrm{NOFe}$ C, 74.85, H, 5.31, N, 3.23. Found: C, 74.79, H, 5.27, N, 3.18.

1-Ferrocenyl-3-(N, N-di-methylphenyl)-2-propen-1one (2): m.p.: $162{ }^{\circ} \mathrm{C}$; EI-MS m/z (rel. int. \%): 360 (72) [M + $1^{+}$.; IR (KBr, $\left.v_{\max }, \mathrm{cm}^{-1}\right): 3138(\mathrm{C}-\mathrm{H}), 2803(\mathrm{C}-\mathrm{H}), 1609$ $(\mathrm{C}=\mathrm{O}), 1557(\mathrm{C}=\mathrm{C}) ;{ }^{1} \mathrm{H} \mathrm{NMR}(600 \mathrm{MXz} \mathrm{CDCl}$ ) $)$ : 7.77 (d, $\mathrm{CH}, J=15 \mathrm{~Hz}), 7.56(\mathrm{~d}, \mathrm{CH}, J=7.8 \mathrm{~Hz}), 6.97$ (d, CH, $J=$ $15.6 \mathrm{~Hz}), 6.72(\mathrm{~d}, \mathrm{CH}, J=7.8 \mathrm{~Hz}), 4.90$ (s, 2H, ferrocene), 4.54 (s, 2H, ferrocene), 4.20 (s, 5H, ferrocene), 3.04 (s, N$\left.\mathrm{CH}_{3}\right) ;{ }^{13} \mathrm{C} \mathrm{NMR}\left(\mathrm{CDCl}_{3}\right) \delta: 193.13,151.76,141.60,130.05$, 122.89, 118.04, 111.92, 81.26, 77.23, 77.02, 76.80, 72.25, 70.01, 69.60, 40.20; Anal. (\%) calc. for $\mathrm{C}_{21} \mathrm{H}_{21} \mathrm{NOFe}$ : C, 70.22, H, 5.85, N, 3.90. Found: C, 70.16, H, 5.79, N, 3.85.

in vitro Screening: Disc-diffusion and micro dilution assay: Antibacterial activity was done by the disk diffusion method with minor modifications. S. aureus, S. pyogenes, $S$. typhimurium and E. coli were sub-cultured in BHI medium and incubated for $18 \mathrm{~h}$ at $37^{\circ} \mathrm{C}$, and then the bacterial cells were suspended, according to the McFarland protocol in saline solution to produce a suspension of about $10^{-5} \mathrm{CFU} \mathrm{mL}^{-1}: 10$ $\mu \mathrm{L}$ of this suspension was mixed with $10 \mathrm{~mL}$ of sterile nutrient agar at $40{ }^{\circ} \mathrm{C}$ and poured onto an agar plate in a laminar flow cabinet. Five paper disks (6 mm diameter) were fixed onto nutrient agar plate. $1 \mathrm{mg}$ of each test compound was dissolved in $100 \mu \mathrm{L}$ DMSO to prepare stock solution from stock solution different concentration $10,20,25,50$, and $100 \mu \mathrm{g} / \mu \mathrm{L}$ of each test compound were prepared. These compounds of different concentration were poured over disk plate on to it. Chloramphenicol (30 $\mu \mathrm{g} /$ disk) was used as standard drug (positive control). DMSO poured disk was used as negative control. The susceptibility of the bacteria to the test compounds was determined by the formation of an inhibitory zone after $18 \mathrm{~h}$ of incubation at $36^{\circ} \mathrm{C}$ reports the inhibition zones $(\mathrm{mm})$ of each compound and the controls. The minimum inhibitory concentration (MIC) was evaluated by the macro dilution test using standard inoculums of $10^{-5} \mathrm{CFL} \mathrm{mL}^{-1}$. Serial dilutions of the test compounds, previously dissolved in dimethyl sulfoxide were prepared to final concentrations of 512, 256, $128,64,32,16,8,4,2$ and $1 \mu \mathrm{g} / \mathrm{mL}$ to each tube was added $100 \mu \mathrm{L}$ of a $24 \mathrm{~h}$ old inoculum. The MIC, defined as the lowest

\begin{tabular}{lllll}
\multicolumn{5}{c}{ TABLE-1 } \\
\hline Compound No. & & & & \\
\hline
\end{tabular}


concentration of the test compound, which inhibits the visible growth after $18 \mathrm{~h}$, was determined visually after incubation for $18 \mathrm{~h}$, at $37^{\circ} \mathrm{C}$. Dimethyl sulfoxide and chloramphenicol were using as negative and positive controls.

\section{RESULTS AND DISCUSSION}

Chalcone derivatives were synthesized by the reaction of acetyl ferrocene and corresponding active aldehyde (Scheme-I and Table-1). The purified product was characterized by the FT-IR, ${ }^{1} \mathrm{H}$ NMR, ${ }^{13} \mathrm{C}$ NMR and EI-MS spectra. The IR spectrum of compounds ( $\mathbf{1}$ and $\mathbf{2}$ ) shows the characteristic band. The $v(\mathrm{C}=\mathrm{O})$ peak of acetyl ferrocene observed at $1668 \mathrm{~cm}^{-1}$ shifts to a lower frequency of $1685-1609 \mathrm{~cm}^{-1}$ of chacones. This is due to the conjugation of the $\pi$-electrons on the benzene moiety with those on the ethylene moiety in the enon linkage. ${ }^{1} \mathrm{H}$ NMR spectra, which prove diagnostic tool for the positional elucidation of the proton. Assignments of the signals are based on chemical shift and intensity pattern. The ${ }^{1} \mathrm{H}$ NMR spectra of all the compound (1 and $\mathbf{2}$ ) measured at room temperature shows two doublets at 7.75-8.06 ppm $(J=15.6)$ for the $\mathrm{CH}=\mathrm{C}$ and $6.90-7.21 \mathrm{ppm}(J=15.6 \mathrm{~Hz})$ for the $\mathrm{CO}=\mathrm{CH}$ indicating that the ethylene moiety in the enon linkage is in the transconformation which conform the formation of mono and bis chalcone.

${ }^{13} \mathrm{C}$ NMR $\left(\mathrm{CDCl}_{3}\right)$ spectra of chalcones $(\mathbf{1}$ and $\mathbf{2})$ were recorded in $\mathrm{CDCl}_{3}$ and spectral signals are in good agreement with the probable structures details of ${ }^{13} \mathrm{C}$ NMR spectra of all compounds and those data are given in the experimental section.

Spectral behavior of ferocenyl chalcones in different media: Absorption and emission spectra of $1 \times 10^{-5} \mathrm{~mol} \mathrm{dm}^{-3}$ compounds ( $\mathbf{1}$ and $\mathbf{2}$ ) in various non-polar, polar aprotic and protic solvents were studied (Figs. 1 and 2). Calculated physicochemical parameters obtained from steady state absorption and fluorescence spectra are tabulated in Tables 2 and 3. A close examination of Figs. 1 and 2 displays that the polarity of



Fig. 1. Electronic absorption spectra of $1 \times 10^{-5} \mathrm{~mol} \mathrm{dm}^{-3}$ of compound $\mathbf{1}$ in different solvents

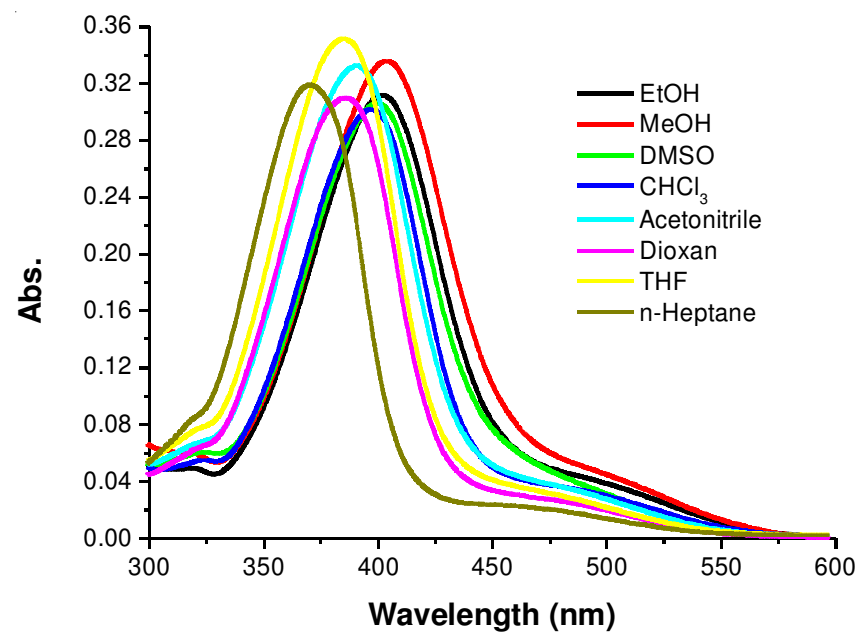

Fig. 2. Electronic absorption spectra of $1 \times 10^{-5} \mathrm{~mol} \mathrm{dm}^{-3}$ of compound 2 in different solvents

TABLE-2

SPECTRAL DATA OF COMPOUND NO. 1 IN DIFFERENT SOLVENTS

\begin{tabular}{ccccccccc}
\hline Solvent & $\Delta \mathrm{f}$ & $\mathrm{E}_{\mathrm{T}}(30) \mathrm{Kcal} \mathrm{mol}^{-1}$ & $\lambda_{\mathrm{ab}}(\mathrm{nm})$ & $\lambda_{\mathrm{em}}(\mathrm{nm})$ & $\varepsilon\left(\mathrm{M}^{-1} \mathrm{~cm}^{-1}\right)$ & $\mathrm{f}$ & $\mu($ Debye $)$ & $\Delta \bar{\nu}\left(\mathrm{cm}^{-1}\right)$ \\
\hline Dioxane & 0.021 & 75.63 & 378 & 488 & 18600 & 0.30 & 4.95 & 4133 \\
$\mathrm{CHCl}_{3}$ & 0.188 & 74.26 & 385 & 484 & 19420 & 0.41 & 5.79 & 5312 \\
$\mathrm{THF}$ & 0.2096 & 75.83 & 377 & 451 & 17850 & 0.34 & 5.25 & 4854 \\
$\mathrm{CH}_{3} \mathrm{CN}$ & 0.304 & 75.43 & 379 & 428 & 19410 & 0.23 & 4.33 & 3020 \\
$\mathrm{DMSO}$ & 0.263 & 74.45 & 384 & 506 & 19310 & 0.48 & 6.27 & 6278 \\
$\mathrm{EtOH}$ & 0.288 & 73.31 & 390 & 544 & 19910 & 0.57 & 6.86 & 7258 \\
$\mathrm{MeOH}$ & 0.308 & 72.93 & 392 & 558 & 19820 & 0.60 & 7.06 & 7589 \\
$n$-Heptane & 0.0004 & 77.27 & 370 & 452 & 20420 & 0.40 & 5.65 & 4903 \\
\hline
\end{tabular}

TABLE-3

\begin{tabular}{|c|c|c|c|c|c|c|c|c|}
\hline \multicolumn{9}{|c|}{$\begin{array}{c}\text { TABLE-3 } \\
\text { SPECTRAL DATA OF COMPOUND NO. } 2 \text { IN DIFFERENT SOLVENTS }\end{array}$} \\
\hline Solvent & $\Delta \mathrm{f}$ & $\mathrm{E}_{\mathrm{T}}(30) \mathrm{Kcal} \mathrm{mol}^{-1}$ & $\lambda_{\mathrm{ab}}(\mathrm{nm})$ & $\lambda_{\mathrm{em}}(\mathrm{nm})$ & $\varepsilon\left(\mathrm{M}^{-1} \mathrm{~cm}^{-1}\right)$ & $\mathrm{f}$ & $\mu$ (Debye) & $\Delta \bar{\nu}\left(\mathrm{cm}^{-1}\right)$ \\
\hline Dioxane & 0.021 & 72.01 & 397 & 504 & 30690 & 0.65 & 7.42 & 5347 \\
\hline $\mathrm{CHCl}_{3}$ & 0.188 & 70.24 & 407 & 534 & 30050 & 0.70 & 7.78 & 5843 \\
\hline THF & 0.2096 & 72.19 & 396 & 514 & 34800 & 0.80 & 8.22 & 5797 \\
\hline $\mathrm{CH}_{3} \mathrm{CN}$ & 0.304 & 71.47 & 400 & 558 & 33200 & 0.94 & 8.92 & 7078 \\
\hline DMSO & 0.263 & 70.07 & 408 & 556 & 30660 & 0.80 & 8.35 & 6584 \\
\hline $\mathrm{EtOH}$ & 0.288 & 69.39 & 412 & 557 & 31200 & 0.78 & 8.29 & 6318 \\
\hline $\mathrm{MeOH}$ & 0.308 & 68.89 & 415 & 561 & 33200 & 0.83 & 8.54 & 6271 \\
\hline$n$-Heptane & 0.0004 & 74.84 & 382 & 504 & 31470 & 0.79 & 7.99 & 6336 \\
\hline
\end{tabular}


solvent has slight effect on absorption maxima, indicating the weak polar character of compounds ( $\mathbf{1}$ and $\mathbf{2}$ ) in the ground state. However, the emission spectra of these compounds are broad and red shifted as the solvent polarity increases (Figs. 3 and 4). The red-shift in $n$-heptane to $\mathrm{MeOH}$ indicates that photoinduced intramolecular charge transfer (ICT) occurring in the singlet excited state ${ }^{29}$. As a result, the dipole moment of compounds (1 and $\mathbf{2}$ ) increases on excitation.

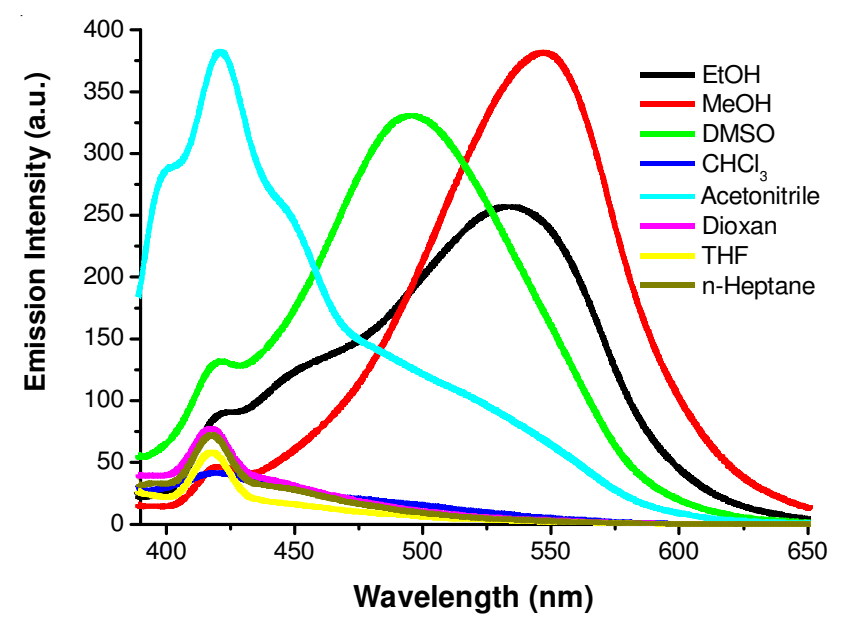

Fig. 3. Emission spectra of $1 \times 10^{-5} \mathrm{~mol} \mathrm{dm}^{-3}$ of compound $\mathbf{1}$ in different solvents

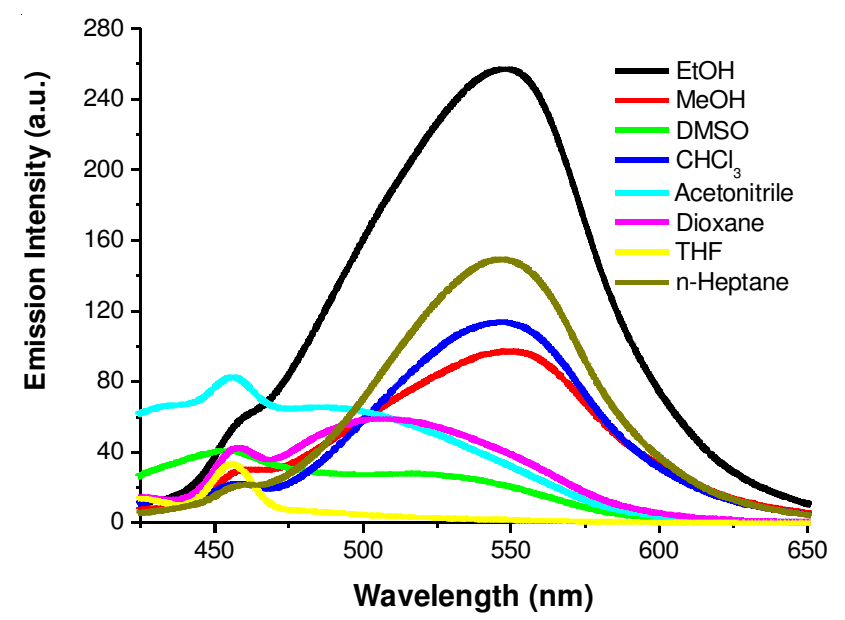

Fig. 4. Emission spectra of $1 \times 10^{-5} \mathrm{~mol} \mathrm{dm}^{-3}$ of compound 2 in different solvents

Determination of dipole moment: The solvatochromic behavior in compound ( $\mathbf{1}$ and $\mathbf{2}$ ) allows one to determine the difference in the dipole moment between the excited singlet and the ground state $\left(\Delta \mu=\mu_{\mathrm{e}}-\mu_{\mathrm{g}}\right)$. This difference can be obtained using the simplified Lippert-Mataga equation as follows ${ }^{29,30}$ :

$$
\begin{gathered}
\Delta \overline{\mathrm{v}}_{\mathrm{st}}=\frac{2\left(\mu_{\mathrm{e}}-\mu_{\mathrm{g}}\right)^{2}}{\mathrm{hca}^{3}} \Delta \mathrm{f}+\text { Const. } \\
\Delta f=\frac{\mathrm{D}-1}{2 \mathrm{D}+1}-\frac{\mathrm{n}^{2}-1}{2 \mathrm{n}^{2}+1}
\end{gathered}
$$

where $\Delta \bar{v}_{\mathrm{st}}$ is the Stokes-shift ${ }^{31}$, which increases with increasing the solvent polarity pointing to stronger stabilization of the excited state in polar solvents, $h$ denotes Planck's constant, $c$ refers to the speed of light in vacuum and $a$ is the Onsager cavity radius. Parameters D and $\mathrm{n}$, in eqn. 2 , correspond to the dielectric constant and refractive index of the solvent, respectively. The Onsager cavity radius was chosen to be 4.2 $\AA$ because this value is comparable to the radius of a typical aromatic fluorophore ${ }^{32}$. Stokes shifts $\left(\Delta \bar{v}_{\mathrm{ss}}\right)$ of compound (1 and 2 ) in different solvents were calculated, as shown in Tables 2 and 3 , using the following the eqn ${ }^{29}$ :

$$
\Delta \overline{\mathrm{v}}_{\mathrm{ss}}=\overline{\mathrm{v}}_{\mathrm{ex}}-\overline{\mathrm{v}}_{\mathrm{em}}
$$

where $\bar{v}_{\text {ex }}$ and $\bar{v}_{\text {em }}$ denote the wavenumbers of excitation and emission maxima $\left(\mathrm{cm}^{-1}\right)$, respectively.

The change in dipole moments $(\Delta \mu)$ between the excited singlet and ground state were calculated as 5.86 and 4.19 Debye for compound $\mathbf{1}$ and $\mathbf{2}$, respectively, indicating that the excited sate of compoun $\mathbf{1}$ and $\mathbf{2}$ is more polor than the ground state.

The effective number of electrons transition from the ground to excited state is usually described by the oscillator strength, which provides the absorption area in the electronic spectrum. The oscillator strength, f, can be calculated using the following equation ${ }^{33}$ :

$$
f=4.32 \times 10^{-9} \int \varepsilon(\bar{v}) d \bar{v}
$$

where $\varepsilon$ is the extinction coefficient $\left(\mathrm{L} \mathrm{mol}^{-1} \mathrm{~cm}^{-1}\right)$, and represents the numerical value of wavenumber $\left(\mathrm{cm}^{-1}\right)$. Oscillator strength values of compounds ( $\mathbf{1}$ and $\mathbf{2}$ ) in different solvents are reported in Tables 2 and 3 . In addition, the transition dipole moment $(\mu$ ) for compound $\mathbf{1}$ and $\mathbf{2}$ from ground to excited state in Debye was estimated in different solvents (Tables 2 and 3 ) using the following relation ${ }^{34}$ :

$$
\mu^{2}=\frac{\mathrm{f}}{4.72 \times 10^{-7} \times \mathrm{E}_{\max }}
$$

where $E_{\max }$ is the energy of maximum absorption expressed in $\mathrm{cm}^{-1}$

Antimicrobial activity: Disc-diffusion and micro dilution assay: The compounds ( $\mathbf{1}$ and $\mathbf{2}$ ) were tested for their antibacterial activities by disc-diffusion method using nutrient broth medium [contained $(\mathrm{g} / \mathrm{L})$ : beef extract $3 \mathrm{~g}$; peptone $5 \mathrm{~g}$; $\mathrm{pH} 7.0]^{35,36}$. The Gram-positive bacteria and Gram-negative bacteria utilized in this study consisted of $S$. aureus, S. pyogenes, $S$. typhimurium and E. coli. The results showed that the nitrogen containing heterocyclic chalcone increased the antibacterial activity. Carbazole containing of chalcone (1) showed good antibacterial activity on $S$. aureus and $S$. pyogenes. The results are presented in Tables 4 and 5 for disc-diffusion method and MIC method.

\section{Conclusion}

Chalcone derivatives were synthesized by the reaction of acetyl ferrocene and corresponding aldehyde under microwave irradiation. In addition, studying spectroscopic and physicochemical properties of chalcone derivatives may show considerable promise towards their potential applications. Compound $\mathbf{1}$ and $\mathbf{2}$ have high molar absorption, large stock shift in emission spectra and the dipole moment of singlet excited state in higher 
TABLE-4

ANTIBACTERIAL ACTIVITY OF COPMPOUND 1 AND 2, POSITIVE CONTROL CHLORAMPHENICOL (CHLORA.) AND NEGATIVE CONTROL (DMSO) MEASURED BY THE HALO ZONE TEST (Unit, mm)

\begin{tabular}{cccc}
\hline \multirow{2}{*}{ Compounds } & & \multicolumn{2}{c}{ Corresponding effect on microorganisms } \\
\cline { 2 - 4 } & S. aureus & S. pyogenes & S. typhimurium \\
\hline $\mathbf{1}$ & $14.2 \pm 0.2$ & $12.2 \pm 0.2$ & $13.5 \pm 0.3$ \\
Chlora. & $10.3 \pm 0.2$ & $11.2 \pm 0.4$ & $9.8 \pm 0.2$ \\
DMSO & $17.0 \pm 0.5$ & $18.2 \pm 0.4$ & $17.2 \pm 0.8$ \\
\hline
\end{tabular}

\begin{tabular}{lccc}
\multicolumn{4}{c}{ TABLE-5 } \\
MINIMUM INHIBITION CONCENTRATION (MIC) \\
OF COMPOUND 1 \& 2, POSITIVE CONTROL: \\
CHLORAMPHENICOL \\
\hline Bacterial & MIC & $\left(\mu \mathrm{g} \mathrm{mL}^{-1}\right)$ & Positive \\
\hline Strain & 1 & 2 & control \\
\hline S. aureus & 128 & 128 & 32 \\
S. pyogenes & 64 & 128 & 32 \\
S. typhimurium & 64 & 128 & 32 \\
E. coli & 128 & 256 & 32 \\
\hline
\end{tabular}

than the ground state. The antibacterial activity of these compounds was investigated using culture of bacteria. Results demonstrated that the nitrogen containing compound increased the antibacterial activity.

\section{ACKNOWLEDGEMENTS}

This project was funded by the Saudi Basic Industries Corporation (SABIC) and the Deanship of Scientific Research (DSR), King Abdulaziz University, Jeddah, under Grant No. 14/308/1433. The authors, therefore, acknowledge with thanks SABIC and DSR technical and financial support.

\section{REFERENCES}

1. S. Vijayakumar, M. Babu, B. Kalluraya and K. Chandrasekharan, Optik, 123, 21 (2012)

2. A.V. Udal'tsov, J. Phtochem. Photoboil. B, 37, 31 (1997).

3. E. Kleinpeter and B.A. Stamboliyska, Tetrahedron, 65, 9211 (2009).

4. X. Zhang, M. Li, Z. Shi, L. Zhao, R. Jin, M. Yi, D. Zhang and Z. Cui, Dyes Pigments, 92, 982 (2012).

5. C. Ravikumar, I.H. Joe and V.S. Jayakumar, Chem. Phys. Lett., 460, 552 (2008).

6. D.A. Svechkarev, I.V. Bukatich and A.O. Doroshenko, J. Photochem. Photobiol. Chem., 200, 426 (2008).

7. H. Xiao, X. Tao, Y. Wang, S. Qian, G. Shi and H. Li, Tetrahedron Lett., 49, 6819 (2008).

8. A.M. Asiri, S.A. Khan, M.S. Al-Amoudi and K.A. Alamry, Bull. Korean Chem. Soc., 33, 1900 (2012).

9. K. Kinashi, K.P. Lee, S. Matsumoto, K. Ishida and Y. Ueda, Dyes Pigments, 92, 783 (2012).

10. N.V. Tkachenko, A.Y. Tauber, H. Lemmetyinen and P.H. Hynninen, Thin Solid Films, 280, 244 (1996).
11. F. Liang, F. Shi, Y. Fu, L. Wang, X. Zhang, Z. Xie and Z. Su, Sol. Energy Mater. Sol. Cells, 94, 1803 (2010).

12. D. Kumar, N.M. Kumar, K. Akamatsu, E. Kusaka, H. Harada and T. Ito, Bioorg. Med. Chem. Lett., 20, 3916 (2010).

13. B. Liu, S. Wu, X. Yu, J. Guan and Q. Kan, J. Coll. Int. Sci., 362, 625 (2011).

14. J. Montes-Avila, S.P. Díaz-Camacho, J. Sicairos-Félix, F. DelgadoVargas and I.A. Rivero, Bioorg. Med. Chem., 17, 6780 (2009).

15. G. Romanelli, G. Pasquale, A. Sathicq, H. Thomas, J. Autino and P. Vazquez, J. Mol. Catal. Chem., 340, 24 (2011).

16. J.T. Li, W.Z. Yang, S.-X. Wang, S.H. Li and T.S. Li, Ultrason. Sonochem., 9, 237 (2002).

17. F.R. Stermitz, J.A. Adamovics and J. Geigert, Tetrahedron, 31, 1593 (1975).

18. A.M. Asiri and S.A. Khan, Mater. Lett., 65, 1749 (2011).

19. E.M. Ebeid, M.H. Abdel-Kader, R.M. Issa and S.A. El-Daly, Chem. Phys. Lett., 146, 331 (1988).

20. A.M. Asiri and S.A. Khan, Molecules, 16, 523 (2011).

21. E.B. Uvarov, D.R. Chapman and A. Isaac, The Penguin Dictionary of Science, N. Middlesex, New York, p. 72 (1982).

22. J.C. Chen, C.Z. Jiang, T.E. Gookin, D.A. Hunter, D.G. Clark and M. Reid, Plant Mol. Biol., 55, 521 (2004).

23. R. Kamakshi, S.S. Latha and B.S. Reddy, Indian J. Chem., 48B, 944 (2010).

24. R. Katsarava, V. Beridze, N. Arabuli, D. Kharadze, C.C. Chu and C.Y. Won, J. Polym. Sci. A Polym. Chem., 37, 391 (1999).

25. D.M. Song, K.I. Jung, J.I. Moon and D.M. Shin, Opt. Mater., 21, 667 (2003).

26. S.A. Khan, A.M. Asiri, K.A. Alamry, S.A. El-Daly and M.A.M. Zayed, Russ. J. Bioorg. Chem., 39, 312 (2013).

27. S.A. Khan and A.M. Asiri, J. Heterocycl. Chem., 49, 1452 (2012).

28. A.M. Asiri, S.A. Khan, H.M. Marwani and K. Sharma, J. Photochem. Photobiol. B, 120, 82 (2013).

29. E. Lippert, Z. Electrochem., 61, 962 (1957).

30. J.K. Dey and S.K. Dogra, Bull. Chem. Soc. Jpn., 64, 3142 (1991).

31. W.E. Acree, D.C. Wilkins, S.A. Tucker, J.M. Griffin and J.R. Powell, J. Phys. Chem., 98, 2537 (1994).

32. S. Kumar, V.C. Rao and R.C. Rastogi, Spectrochim. Acta A, 57, 41 (2001).

33. N.J. Turro, Reading, MA, 286 (1965).

34. B.J. Coe, J.A. Harris, I. Asselberghs, K. Clays, G. Olbrechts, A. Persoons, J.T. Hupp, R.C. Johnson, S.J. Coles, M.B. Hursthouse and K. Nakatani, Adv. Funct. Mater., 12, 110 (2002).

35. (a) S.A. Khan, A.M. Asiri, A.A.P. Khan, K.A. Khan and M.A.M. Zayed, Asian J. Chem., 25, 8643 (2013); (b) A.M. Asiri and S.A. Khan, Molecules, 15, 6850 (2010).

36. S.A. Khan, A.M. Asiri, S. Kumar and K. Sharma, Eur. J. Chem., 5, 85 (2014). 